\title{
Hepatic resection for isolated breast cancer liver metastasis: A single-center experience
}

\author{
Jae Bong Choi', Hyung II Seo', Sung Pil Yun'1, Young Lae Jung', Seok Won Lee', Young Tae Bae', Suk Kim² \\ Departments of 'Surgery and ${ }^{2}$ Radiology, Biomedical Research Institute, Pusan National University Hospital, Pusan National University School of \\ Medicine, Busan, Korea
}

Purpose: The objective of this study was to investigate the outcomes of selected patients with breast cancer liver metastases (BCLM) without extrahepatic metastases after hepatic resection.

Methods: Patients whose imaging findings did not show extrahepatic disease were selected for hepatic resection. If Ro resection was available and the operative risk was low in preoperative tests, the patients underwent surgery.

Results: Between 2011 and 2014, six patients underwent hepatic resection for BCLM. All patients received hepatic resection to achieve an R0 resection. The time interval between initial detection of breast cancer and that of liver metastases in the patients, excluding one patient with synchronous metastases, was 55.2 months. Major liver resection was performed in four patients. Differences were observed in the hormone receptor status between the primary breast tumor and liver metastases; however, no difference was observed in the human epidermal growth factor receptor 2 status. The 1-year and 3-year overall survival rates after hepatic resection were 100\% and $83.3 \%$, respectively. The 1 -year and 3-year disease free survival rates after hepatic resection were $66.7 \%$ and $50.0 \%$, respectively.

Conclusion: Curative resection may be considered as one of the multimodality treatments for BCLM. It shows benefit in selected patients; its selection criteria needs to be investigated.

Keywords: Breast neoplasms, Liver metastasis, Liver resection, Prognosis

\section{INTRODUCTION}

In contrast to the well described guidelines for hepatic resection of colorectal cancer and neuroendocrine liver metastases, surgical resection of breast cancer liver metastases (BCLM) is only considered in highly selected patients $[1,2]$. Treatment for BCLM is mainly based on the physician's experience because of limited clinical benefits of hepatic resection.

Liver metastases occur frequently in women with metastatic breast cancer, which is mostly associated with extrahepatic metastasis. Metastases that occur only in the liver constitute $4 \%-5 \%$ of

Received: Sep 5, 2017 Accepted: Oct 23, 2017

Correspondence to: Hyung-II Seo

Department of Surgery, Biomedical Research Institute, Pusan National University Hospital, Pusan National University School of Medicine, 179 Gudeok-ro, Seo-gu, Busan 49241, Korea

Tel: +82-51-2407238, Fax: +82-51-2471365

E-mail: seohi71@hanmail.net

Copyright (C) Korean Society of Surgical Oncology

This is an Open Access article distributed under the terms of the Creative Commons Attribution Non-Commercial License (http://creativecommons.org/licenses/by-nc/4.0) which permits unrestricted non-commercial use, distribution, and reproduction in any medium, provided the original work is properly cited. metastatic breast cancer cases, and the available treatments for them are limited and ineffective [3-5]. Treatment options for BCLM are hormonal therapy, chemoradiotherapy, radio-frequency ablation therapy, selective internal radiation therapy, and conservative therapy. Despite the multimodality treatments for BCLM, patients with this condition have a poor prognosis with a median survival of 24-33 months [6,7]. Hepatic resection in selected patients with BCLM showed improved outcomes, with a 5 -year survival ranging from $16 \%-61 \%$ [8-21]. The role of liver resection in BCLM cases is still controversial. The aim of this paper was to review the outcomes of selected patients with BCLM after hepatic resection at a single center.

\section{METHODS}

\section{Patients selection}

Patients without extrahepatic disease findings in imaging studies, such as computed tomography (CT), magnetic resonance imaging, bone scintigraphy, and positron emission tomography-CT (PET$\mathrm{CT}$ ), were selected for hepatic resection. If R0 resection was available and there was a low operative risk according to American So- 
ciety of Anesthesiologists physical status I, II during preoperative tests, the patient underwent surgery. This retrospective study was approved by the Institutional Review Board at Pusan National University Hospital Clinical Trial Center (IRB No. H-1702-010-052), and written informed consent was obtained from all participants.

\section{Postoperative follow-up schedule}

Patients underwent a follow-up examination every 6 months, which included the following examinations: physical and laboratory testing (serology, liver function test, and tumor marker test) and radiographic examination (chest X-ray scan, ultrasound, mammography, and bone scintigraphy). CT and PET-CT scans were analyzed if any abnormal findings were identified during the radiographic examination.

\section{Statistical analysis}

The comparison of overall survival was analyzed by the log rank test. P-values less than 0.05 were considered statistically significant. All statistical analyses were performed using the SPSS ver. 23.0 for Windows (IBM Corp., Armonk, NY, USA).

\section{RESULTS}

Six patients who underwent hepatic resection for BCLM between
November 2011 and January 2014. The aim of surgery was to achieve resection with an R0 margin. The median follow-up periods was 42.2 months. The initial diagnosis of all patients were infiltrative ductal carcinoma. Three of the patients underwent breast conserving surgery. Breast cancer lymph node metastases were found in four patients. Two patients yielded negative results for hormone receptors (estrogen receptor $[\mathrm{ER}]$ and progesterone receptor). All patients, except for the patient with synchronous metastases, received adjuvant therapy following breast cancer surgery depending on the hormone receptor status and tumor stage (Table 1). One of the patients (case 2) had synchronous metastases, whereas the remaining five patients had metachronous metastases. The time interval between the initial diagnosis of breast cancer and detection of liver metastases in the patients, excluding the one patient with synchronous metastases, was 55.2 months. Major liver resection (more than three segments) was performed in four patients, and radiofrequency ablation was performed in one patient who had a recurrence of hepatic metastases. All patients received postoperative adjuvant chemotherapy following hepatic resection. Cases 2, 5, and 6 were human epidermal growth factor receptor 2 (HER2)-positive. Trastuzumab was administered after hepatic resection in cases 2 and 5; however, case 6 did not receive trastuzum$\mathrm{ab}$ treatment owing to liver metastases that were found during adjuvant therapy of trastuzumab. Cases 1, 3, and 4 were administered

Table 1. Clinical characteristics of the primary disease

\begin{tabular}{|c|c|c|c|c|c|c|c|c|c|}
\hline Case No. & Sex & Age (yr) & Operation & Pathology & TNM stage & $\begin{array}{l}\text { Differentiation } \\
\text { (grade) }\end{array}$ & ER/PR/HER2 & Adjuvant treatment & $\begin{array}{l}\text { Disease-free } \\
\text { interval (mo) }\end{array}$ \\
\hline 1 & Female & 53 & MRM & IDC & T3N3M0 & Moderately & $3 / 3 / 0$ & AC/docetaxel & 43 \\
\hline 2 & Female & 55 & MRM & IDC & T2NoM1 & Poorly & 0/0/3 & - & 0 \\
\hline 3 & Female & 46 & $\mathrm{BCS}$ & IDC & T3N3M0 & Poorly & $3 / 3 / 0$ & $A C \rightarrow$ Taxol & 26 \\
\hline 4 & Female & 56 & $\mathrm{BCS}$ & IDC & T1NOMO & Moderately & $1 / 2 / 0$ & Taxotere $\rightarrow A C$ & 160 \\
\hline 5 & Female & 43 & BCS & IDC & T2N1M0 & Poorly & $1 / 0 / 3$ & AC $\rightarrow$ unitaxel & 30 \\
\hline 6 & Female & 55 & MRM & IDC & $\mathrm{T} 2 \mathrm{~N} 2 \mathrm{MO}$ & Moderately & 0/0/3 & $\mathrm{AC} \rightarrow$ unitaxel $\rightarrow$ trastuzumab & 17 \\
\hline
\end{tabular}

TNM, tumor node metastasis; ER, estrogen receptor; PR, progesterone receptor; HER2, human epidermal growth factor receptor 2; MRM, modified radical mastectomy; IDC, infiltrative ductal carcinoma; AC, adriamycin; BCS, breast conserving surgery.

Table 2. Clinical characteristics of the secondary disease

\begin{tabular}{|c|c|c|c|c|c|c|c|}
\hline Case & ASA score & $\begin{array}{l}\text { Type of hepatic } \\
\text { resection }\end{array}$ & $\begin{array}{l}\text { ER/PR/ } \\
\text { HER2 }\end{array}$ & Size $(\mathrm{cm})$ & LVI/PNI & $\begin{array}{l}\text { Recurrence after hepatic resection } \\
\text { (months to recurrence after surgery) }\end{array}$ & Survival (mo) \\
\hline 1 & 1 & Rt. hemihepatectomy & 0/0/0 & 5.5 & $-1-$ & Liver (9) & 60 (Live) \\
\hline 2 & 2 & Partial resection & 0/0/3 & 3.3 & $+1-$ & NED & 35 (Live) \\
\hline 3 & 2 & Partial resection & 0/0/0 & $2.5 / 1 / 1$ & $+1-$ & Bone/liver (29) & 42 (Live) \\
\hline 4 & 2 & Lt. hemihepatectomy & $1 / 0 / 0$ & 3.3 & $-1-$ & NED & 42 (Live) \\
\hline 5 & 1 & Lt. hemihepatectomy & 0/0/3 & $2 / 1.2$ & $+/+$ & Liver/lung/LN (6) & 19 (Dead) \\
\hline 6 & 2 & Lt. hemihepatectomy & 0/0/3 & 2.7 & $-1-$ & NED & 54 (Live) \\
\hline
\end{tabular}

ASA, American Society of Anesthesiologists; ER, estrogen receptor; PR, progesterone receptor; HER2, human epidermal growth factor receptor 2; LVI, lymphvacular invasion; PNI, perineural invasion; Rt., right; NED, no evidence of disease; Lt., left; LN, lymph node. 

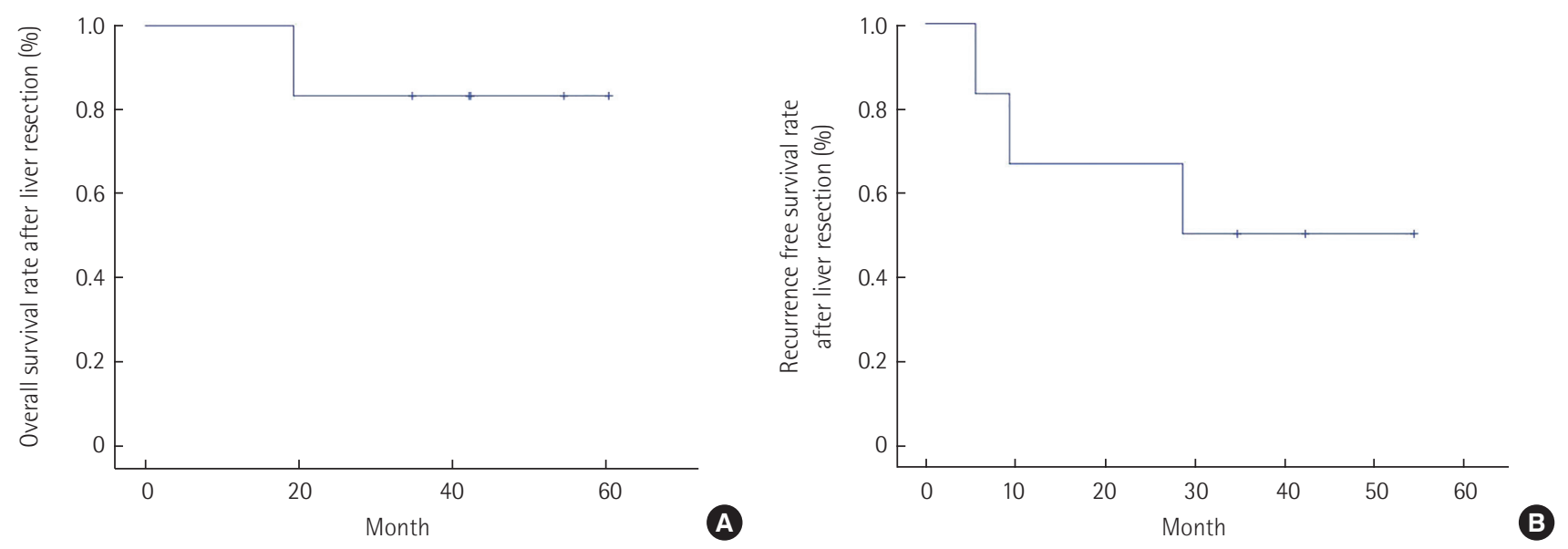

Fig. 1. (A) The 1-year and 3-year overall survival rates after hepatic resection were 100\% and 83.3\%, respectively. (B) The 1-year and 3-year disease free survival rates after hepatic resection were $66.7 \%$ and $50.0 \%$, respectively.

cytotoxic agents following hepatic resection. Hormone receptor status differed between the primary breast tumor and liver metastases, but no difference was observed for HER2 status. Case 5 was diagnosed as perineural invasion (PNI) positive after analyses of the resected liver specimen, and this patient showed an earlier and more aggressive pattern of recurrence. The first site for recurrence after hepatic resection was liver, and then metastases in other organs were detected in the imaging studies (Table 2). The 1-year and 3-year overall survival rates and disease-free survival rates after hepatic resection were $100 \%$ and $83.3 \%$, and $66.7 \%$ and $50.0 \%$, respectively (Fig. 1).

\section{DISCUSSION}

The liver is the primary metastatic site in $12 \%-15 \%$ of patients with breast cancer, but isolated liver metastasis occurs in approximately $5 \%$ of patients. There are many retrospective, non-randomized studies that reported an improvement in the survival of patients who underwent liver resection for BCLM, compared with those who only received systemic treatment. Five-year survival rates following liver resection have been reported to be between $16 \%$ and $61 \%[6,7,21]$, and hepatic resection for BCLM may be an option in the multimodality treatment of BCLM.

In contrast to the well-described guidelines for hepatic resection of colorectal cancer liver metastasis, guidelines for hepatic resection of BCLM are mainly based on individual institutional and personal experience. Furthermore, the data hepatic resection of BCLM is limited because the numbers of available retrospective reports and enrolled patients are less. Researchers agree that curative hepatic resection for BCLM may be limited to isolated hepatic metastases and in patients with low operative risk. Recently, sys- temic review reported by Yoo et al. [22] described that liver resection for BCLM should be considered in patients with isolated liver metastases as the evidence suggests that their survival is improved compared to chemotherapy alone, and this study reported that the median 1- and 3-year overall survival were $90 \%$ and $56 \%$, respectively. Our study satisfied these conditions, as can be seen with the relatively high survival rate observed after liver resection. The 1-year and 3-year overall survival rates and disease-free survival rates after hepatic resection were $100 \%$ and $83.3 \%$, and $66.7 \%$ and $50.0 \%$, respectively.

Although variable prognostic factors (patient age, number and size of metastases, lymph node infiltration, stage of primary disease, prior local recurrence of the primary tumor, and clear resection margin of metastatic lesion) have been suggested in some reports, many authors describe the importance of hormone receptor status as a prognostic factor for the primary tumor after complete resection of BCLM [12,17,20]. Golse and Adam [23] suggested that the best results after the resection of BCLM are achieved after applying selection criteria based on small metastases $(<4-5 \mathrm{~cm})$, minor hepatectomy, radical resection (ideally R0, or R1), stable disease after neoadjuvant therapy, and a delay between primary and secondary lesions longer than 1 or 2 years. Howerver, the age of the patient, her hormone receptor status, and HER2 overexpression are not strong predictors of overall survival [23]. In our study, time to recurrence was relatively short if the metastatic lesion was larger than $5 \mathrm{~cm}$, or there were multiple lesions (cases 1, 3, and 5). Case 5 was diagnosed as PNI positive after analyses of the resected liver specimen, and this case who was PNI-positive, not only showed early recurrence, but also showed more aggressive disease course. Koca et al. [24] described that grade III, perineural invasion, and lymph node were significantly associated with disease 
free survival, and the presence of PNI was found to have borderline significance on overall survival. However, we could not analyze the prognostic factors following hepatic resection owing to the small number of patients. There was a significant difference in hormone receptors between the resected liver specimens and primary breast tumors, but no difference in the HER2 status. Therefore, targeted therapy for HER2 should be continued if the metastases are positive for HER2 receptors in the resected liver specimen. Similarly, hormone therapy should be continued if the metastatic lesion is hormone positive. Recently, Spolverato et al. [25] reported that liver resection plus conventional systemic therapy was more cost effective for patients with ER-positive than systemic therapy alone. However, for patients with HER2 overexpression, liver resection plus systemic therapy that included trastuzumab had a cost-effectiveness that was comparable to conventional systemic therapy alone [25].

Some studies have reported that the presence of extrahepatic metastatic lesions was a significant prognostic factor for breast cancer $[26,27]$. The 1-year and 3-year survival rates of patients with extrahepatic metastases were $60.0 \%$ and $20.0 \%$, respectively [26]. In this study, liver metastases were restricted to cases where no other distant or extrahepatic metastases were present, and the 1-year and 3-year overall survival rates after hepatic resection were $100 \%$ and $83.3 \%$, respectively. We think that surgical treatment of the liver metastases in breast cancer should be considered in carefully selected patients.

This study had some limitations. First, this was a retrospective study. Second, owing to the small numbers of patients, no statistical comparisons could be made. Although this study contains a small number of patients and has limitations, it suggests that surgery in patients with liver metastases, without extrahepatic metastases, can result in a good prognosis.

Curative resection of BCLM may be considered a multimodal treatment of the metastatic disease. It has benefits for a distinct set of patients, and the criteria for patient selection should be further investigated.

\section{CONFLICT OF INTEREST}

No potential conflict of interest relevant to this article was reported.

\section{ACKNOWLEDGMENTS}

This work was supported by clinical research grant from Pusan National University Hospital 2016.

\section{REFERENCES}

1. House MG, Ito H, Gonen M, Fong Y, Allen PJ, DeMatteo RP, et al. Survival after hepatic resection for metastatic colorectal cancer: trends in outcomes for 1,600 patients during two decades at a single institution. J Am Coll Surg 2010;210:744-55.

2. Morris EJ, Forman D, Thomas JD, Quirke P, Taylor EF, Fairley L, et al. Surgical management and outcomes of colorectal cancer liver metastases. Br J Surg 2010;97:1110-8.

3. Zinser JW, Hortobagyi GN, Buzdar AU, Smith TL, Fraschini G. Clinical course of breast cancer patients with liver metastases. J Clin Oncol 1987;5:773-82.

4. Pivot X, Asmar L, Hortobagyi GN, Theriault R, Pastorini F, Buzdar A. A retrospective study of first indicators of breast cancer recurrence. Oncology 2000;58:185-90.

5. Pagani O, Senkus E, Wood W, Colleoni M, Cufer T, Kyriakides S, et al. International guidelines for management of metastatic breast cancer: can metastatic breast cancer be cured? J Natl Cancer Inst 2010;102:456-63.

6. Campos SM, Guastalla JP, Subar M, Abreu P, Winer EP, Cameron DA. A comparative study of exemestane versus anastrozole in patients with postmenopausal breast cancer with visceral metastases. Clin Breast Cancer 2009;9:39-44.

7. Crump M, Gluck S, Tu D, Stewart D, Levine M, Kirkbride P, et al. Randomized trial of high-dose chemotherapy with autologous peripheral-blood stem-cell support compared with standard-dose chemotherapy in women with metastatic breast cancer: NCIC MA.16. J Clin Oncol 2008;26:37-43.

8. Adam R, Aloia T, Krissat J, Bralet MP, Paule B, Giacchetti S, et al. Is liver resection justified for patients with hepatic metastases from breast cancer? Ann Surg 2006;244:897-907.

9. Caralt M, Bilbao I, Cortes J, Escartin A, Lazaro JL, Dopazo C, et al. Hepatic resection for liver metastases as part of the "oncosurgical" treatment of metastatic breast cancer. Ann Surg Oncol 2008;15: 2804-10.

10. Elias D, Maisonnette F, Druet-Cabanac M, Ouellet JF, Guinebretiere JM, Spielmann M, et al. An attempt to clarify indications for hepatectomy for liver metastases from breast cancer. Am J Surg 2003;185:158-64.

11. Ercolani G, Grazi GL, Ravaioli M, Ramacciato G, Cescon M, Varotti G, et al. The role of liver resections for noncolorectal, nonneuroendocrine metastases: experience with 142 observed cases. Ann Surg Oncol 2005;12:459-66.

12. Hoffmann K, Franz C, Hinz U, Schirmacher P, Herfarth C, Eichbaum $\mathrm{M}$, et al. Liver resection for multimodal treatment of breast cancer metastases: identification of prognostic factors. Ann Surg Oncol 2010;17:1546-54. 
13. Lubrano J, Roman H, Tarrab S, Resch B, Marpeau L, Scotte M. Liver resection for breast cancer metastasis: does it improve survival? Surg Today 2008;38:293-9.

14. Martinez SR, Young SE, Giuliano AE, Bilchik AJ. The utility of estrogen receptor, progesterone receptor, and Her-2/neu status to predict survival in patients undergoing hepatic resection for breast cancer metastases. Am J Surg 2006;191:281-3.

15. Sakamoto Y, Yamamoto J, Yoshimoto M, Kasumi F, Kosuge T, Kokudo N, et al. Hepatic resection for metastatic breast cancer: prognostic analysis of 34 patients. World J Surg 2005;29:524-7.

16. Selzner M, Morse MA, Vredenburgh JJ, Meyers WC, Clavien PA. Liver metastases from breast cancer: long-term survival after curative resection. Surgery 2000;127:383-9.

17. Thelen A, Benckert C, Jonas S, Lopez-Hanninen E, Sehouli J, Neumann $\mathrm{U}$, et al. Liver resection for metastases from breast cancer. J Surg Oncol 2008;97:25-9.

18. Verhoef C, Kuiken BW, JN IJ, de Wilt JH. Partial hepatic resection for liver metastases of non-colorectal origin, is it justified? Hepatogastroenterology 2007;54:1517-21.

19. Vlastos G, Smith DL, Singletary SE, Mirza NQ, Tuttle TM, Popat RJ, et al. Long-term survival after an aggressive surgical approach in patients with breast cancer hepatic metastases. Ann Surg Oncol 2004;11:869-74.

20. Weitz J, Blumgart LH, Fong Y, Jarnagin WR, D’Angelica M, Harri- son LE, et al. Partial hepatectomy for metastases from noncolorectal, nonneuroendocrine carcinoma. Ann Surg 2005;241:269-76.

21. Yoshimoto M, Tada T, Saito M, Takahashi K, Uchida Y, Kasumi F. Surgical treatment of hepatic metastases from breast cancer. Breast Cancer Res Treat 2000;59:177-84.

22. Yoo TG, Cranshaw I, Broom R, Pandanaboyana S, Bartlett A. Systematic review of early and long-term outcome of liver resection for metastatic breast cancer: Is there a survival benefit? Breast 2017;32:162-72.

23. Golse N, Adam R. Liver metastases from breast cancer: what role for surgery? Indications and results. Clin Breast Cancer 2017;17: 256-65.

24. Koca E, Kuzan TY, Dizdar O, Babacan T, Sahin I, Ararat E, et al. Outcomes of locally advanced breast cancer patients with $\geq 10$ positive axillary lymph nodes. Med Oncol 2013;30:615.

25. Spolverato G, Vitale A, Bagante F, Connolly R, Pawlik TM. Liver resection for breast cancer liver metastases: a cost-utility analysis. Ann Surg 2017;265:792-9.

26. Kim JY, Park JS, Lee SA, Kim JK, Jeong J, Yoon DS, et al. Does liver resection provide long-term survival benefits for breast cancer patients with liver metastasis? A single hospital experience. Yonsei Med J 2014;55:558-62.

27. Treska V, Cerna M, Kydlicek T, Treskova I. Prognostic factors of breast cancer liver metastasis surgery. Arch Med Sci 2015;11:683-5. 